\title{
Automatic Headlight Dimmer Using Arduino and LDR Sensor
}

\author{
B.Kalaimathi ${ }^{\mathrm{a}}$, Dr.M. Kasiselvanathan ${ }^{\mathrm{b}}$, R. Swetha ${ }^{\mathrm{c}}$, R. Shobika ${ }^{\mathrm{d}}$, S. Swetha ${ }^{\mathrm{e}}$ \\ ${ }^{a}$ Assistant Professor, Department of Electronics and Communication Engineering, Sri Ramakrishna Engineering \\ College, Coimbatore, India. E-mail: kalaimathi@srec.ac.in, kasiselvanathan@ gmail.com \\ ${ }^{\mathrm{b}}$ Assistant Professor, Department of Electronics and Communication Engineering, Sri Ramakrishna Engineering \\ College, Coimbatore, India. \\ c,d,e UG Student, Department of Electronics and Communication Engineering, Sri Ramakrishna Engineering \\ College, Coimbatore, India.
}

Article History: Received: 11 January 2021; Accepted: 27 February 2021; Published online: 5 April 2021

\begin{abstract}
The main objective of this paper is to design the prototype model of the Automatic headlight dimmer. While travelling during night times the head light of the upcoming vehicle hits the eyes of the driver from the opposite end. Sometimes this bright light from the opposite vehicle causes glare to the drivers and it leads to accident. The sudden glare which the driver experienced is called Troxler Effect. Many reports say that the accidents in roadways during night times are mainly caused by this Troxler Effect. In order to provide safety to the drivers and also for a comfortable travel this model is proposed. It can be achieved by using an LDR sensor. The LDR sensor which acts as a variable resistant that converts the high beam of the upcoming vehicle's headlight to low beam with the help of Arduino UNO and other components. This system will be a useful in the area of automobile and brings a new trend to ensure the safety of the drivers.
\end{abstract}

Keywords: LDR Sensor, Arduino, ATmega328, LED, Relay, Troxler Effect.

\section{Introduction}

Transportation is an essential part of our life. Nothing can be done without travelling and to be safe while driving. The night travel is quite difficult than day travel because of the darkness in night time. Accidents are commonly takes place in all over world and many takes place during night time. It is due to that sudden glare from the oncoming vehicle ${ }^{1}$.

An automatic headlight system is used to senses the light intensity value of opposite vehicles and automatically switches the high beam into low beam and it will reduces the glare effect ${ }^{2}$. A Graphene coated LED based automatic street lighting system is proposed using Arduino microcontroller. In this the author introduced GaN based LED which acts as a heat sink. They have used Arduino UNO Microcontroller ${ }^{3}$. The design and implementation of automatic headlight dimmer for vehicles using light dependent resistor (LDR) sensor. The device is able to automatically switch the headlight low when it is sensed by the light dependent resistor $^{4}$. An automatic head light dipper with respect to upcoming vehicles response is dealt. In this author uses LDR for sensing weather the light is low or high beam. The circuits will intimate the LDR which the light is in upper mode it will changes to dipper mode 5 .

A system uses LED and LDR. LED is a diode which works based on the concept of Electro luminescence ${ }^{6}$. Intelligent Street Lightening System LDR is used for save power and energy. Control system is used for on and off the street lights ${ }^{7}$. Design and Development of Intelligent Wireless Street Light Control and Monitoring System are proposed along With GUI ${ }^{8}$. The limitations of probable vehicle head light technologies are proposed. It gives the methods for controlling the intensity of lights during night times ${ }^{9}$. An Optimal Light Power Consumption Using LDR is discussed based on the intensity of light present on the environment ${ }^{10 .}$ The lowCost Solar Irradiance Meter using LDR Sensors is provided when the amount of solar irradiance reaches beyond the desired value the solar panel stop ${ }^{11}$

The existing method for headlight dimmer is manual switching. In that existing method we have to control the switch from high beam to low beam manually. It will be very difficult to do in all times. This prototype is prepared to reduce the manual complexion during driving and also to avoid accidents. Here the major components are LDR sensor, relay, Atmega328. These components are the highlighting part of our system. Where Atmega328 is a microcontroller which controls the system. The purpose of relay is for switching since it is a switching device. In order to build the system these are the required things.

To make this switching easier and also in an efficient way we have implemented this model. This model will easy to setup and doesn't require a large maintenance. Its main objective is to switch the headlight of the high beam to a low beam whenever there will be an opposite vehicle approaching. And it also automatically switches back to high beam when the vehicles passes over. The device is done with less number of components and portable, it is also cost efficient. So that this device will fill a good place in a market level. Peoples becomes more useful with this device. To control the intensity of the head light, we must ensure that: 
i. The correct setup of the device.

ii. Uninterrupted power supply.

By these requirements we will find the value that need to be measured.

\section{Methods}

\section{A. Principle of Operation}

The basic principle of operation is can be done where we have to correctly assemble the components as per the block diagram as shown in figure.1. The LDR is a variable resistant when it is connected to the resistors it acts as a voltage divider. For that the transistor BC547 is used to balance the network. Which is also connected to the Relay circuit. In Arduino the program is coded using embedded $\mathrm{C}$ to control the switching of the light. And other two LEDs are connected to the other end of the relay circuit. Each LED represents the high and low beam which is used for indication purpose for example red and green. Whether the headlight is in high beam the red LED will glow for low beam green LED will glow.

The comparator is the basic operation with the transistor and the LED bulbs. When the high intensity beam falls on the LDR there will be a potential drop and that triggers the transistor. The transistors works on conduction mode to switch the relay. When there is no approaching vehicle the transistor will not trigger.

\section{B. Working of the Circuit}

Based on the principle the actual working model is constructed. The same components are used as mentioned earlier in the principle. For current source purpose we have used $12 \mathrm{~V}$ adapter here. But in real time power can be taken from the car battery. The Arduino coding is used to control the switching of the headlight.

\section{Case 1:}

When our vehicle is approaching other vehicle with high intensity, then the high intensity is sensed by the LDR sensor which makes the circuit potentially unstable. That will trigger the transistor BC547 which is connected to the relay circuit. Due to the triggering of the transistor that green bulb will glows and thus indicates that our headlight is switches from high to low.

\section{Case 2:}

When there is no approaching car then there will be a potentially balanced circuit network. Triggering will not take place therefore the green led switches to red indicate that the headlight is turned low to high beam.

\section{Components}

The implementation device contains simple components like:

- LDR Sensor

- Arduino

- Relay.

- Transistors BC547.

- Resistors

- LED lights.

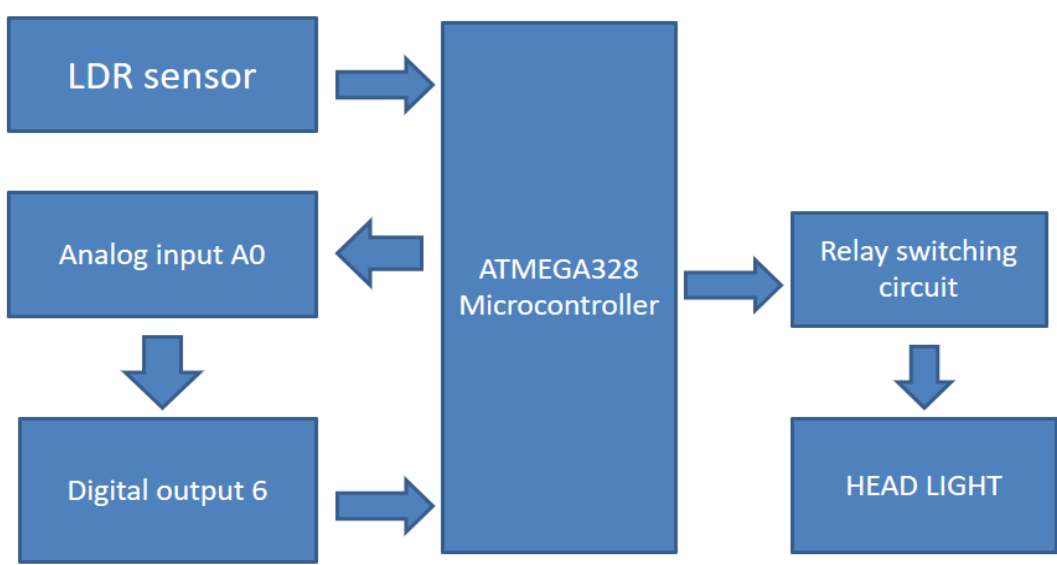

Figure 1. Block Diagram 


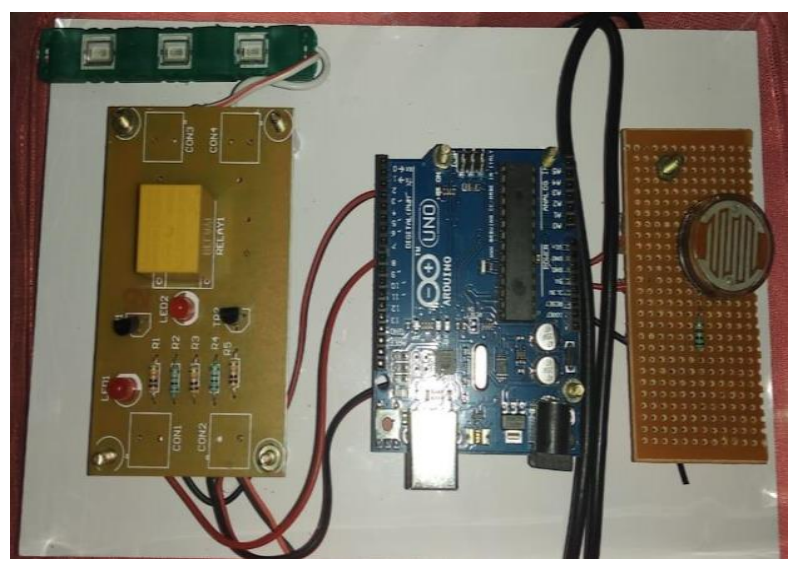

Figure 2. Prototype

When the components are connected as per the block diagram and the power supply is given the device starts to work their respective functions and indicate the current state of the headlight. It is a very simple device there will not be any large expenses and it is easy to setup. The prototype model is shown in figure. 2 .

\section{Results and Discussion}

While driving during night time glare is a serious problem for drivers.It can be overcome by automatic switching of the headlight to low beam, when it senses a vehicle approaching from opposite side with high beam. The implemented result is shown in figure.3. Use of these automated headlights results in convenience to the driver while driving at night. And at the same time it reduces the accidents. Maintenance of this device is also easy.

There are 3 states that describes the situation and its act:

a. Both the vehicles at high beam.

b. Both the vehicles in low beam.

c. After passing both the vehicles becomes high beam.

\section{a. Both the vehicles at high beam:}

In this state the vehicles approaching each other with high beam. Then the high beam is detected using LDR sensor.

\section{b. Both the vehicles in low beam:}

In this state the high beam is detected using the sensor and then it switches to low beam immediately.

\section{c. After passing both the vehicles becomes high beam:}

Here when the vehicles back to the track where there is no oncoming high beam vehicle it switches from low to high beam automatically.

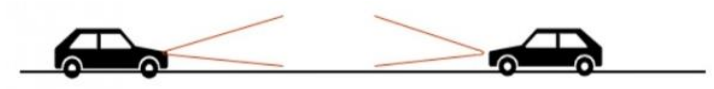

a.) Both Vehicles at High Beam

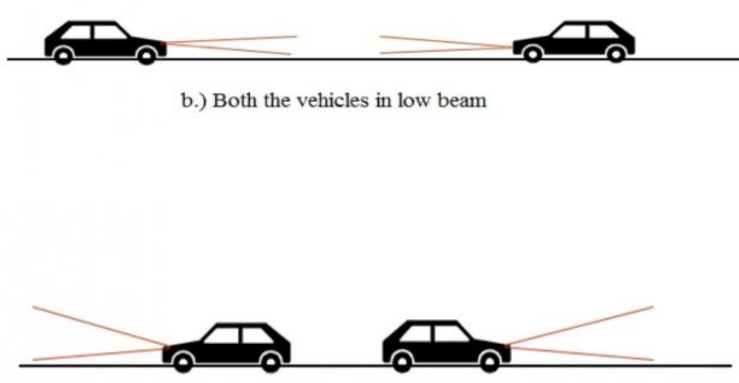

c.) After passing both vehicles becomes high beam.

Figure 3. Implementation Result 


\section{Conclusion}

This prototype is implemented which helps the driver to use headlight automatically switches the high to low beam when it senses a vehicle approaching from the opposite side. The circuit consists of simple and economical components which can be easily installed. The working and implementation of the prototype are discussed in detail. The implementation of this device in automobile field will brings safety and avoids accidents.

\section{References}

1. Akinsanmi, O., Ganjang, A.D., \& Ezea, H.U. (2015). Design and development of an automatic automobile headlight switching system. International Journal of Engineering and Applied Sciences, 2(8), 257837.

2. AslamMusthafa R, Bala Krishnan T, Seetha Raman N, Shankar M, Swathi R, "Automatic Headlight Beam Controller" Special Issue Published in International Journal of Trend in Research and Development (IJTRD) 15th March 2017.

3. Riyaz, M.A.K., Jeyakumar, S.A., Sharik, M.A.H., Tamilarasi, A. (2017). Graphene Coated LED based Automatic Street Lighting System using Arduino Microcontroller. IEEE International Conference on Power, Control, Signals and Instrumentation Engineering (ICPCSI-2017).

4. Sk, O., Ea, W., \& Kumassah, F. (2016). Design and implementation of automatic headlight dimmer for vehicles using light dependent resistor (LDR) sensor. International Journal of Emerging Technology and Innovative Engineering, 2(4).

5. Pushpanjali, G.M., Mali, P.S., \& Naman, R.R. (2016). Automatic Headlight Dipper with Respect to Upcoming Vehicles. Response International Journal on Emerging Technologies (Special Issue on ICRIET-2016).

6. Malhotra, S., \& Taneja, S. (2014). Automatic Brightness Control Using LDR Sensors. Advanced Research in Electrical and Electronic Engineering, 1(2), 12-13.

7. Srivastava, S. (2013). Automatic street lights. Advance in electronic and electric engineering, 3(5), 539342.

8. Subramanyam, B.K., Reddy, K.B., \& Reddy, P.A.K. (2013). Design and development of intelligent wireless street light control and monitoring system along with gui. International Journal of Engineering Research and Applications (IJERA), 3(4), 2115-2119.

9. Sarma, C., Gupta, A., Singh, A., Bhattacharjee, I., Mohanta, A., Tripathy, S., \& Singhal, D. (2018). Limitations of Probable Vehicle Headlight Technologies-A Critical Review. In IOP Conference Series: Materials Science and Engineering, 390(1), 012073.

10. Salim, G.M., Ismail, H., Debnath, N., \& Nadya, A. (2015). Optimal light power consumption using LDR sensor. In 2015 IEEE International Symposium on Robotics and Intelligent Sensors (IRIS), 144148.

11. de Barros, R.C., Callegari, J.M.S., do Carmo Mendonca, D., Amorim, W.C.S., Silva, M.P., \& Pereira, H.A. (2018). Low-cost solar irradiance meter using LDR sensors. In 2018 13th IEEE International Conference on Industry Applications (INDUSCON), 72-79. 